\title{
A Palaeomagnetic Consideration on the Remanent Magnetism of the Basalt Lavas at Kawajiri-misaki, Japan
}

\author{
By Eizo ASAMI \\ Department of Guidance, Kyoto University
}

(Read Oct. 16, 1956; Received, Nov. 4, 1956)

\begin{abstract}
On the outcrop of the basalt lavas at Kawajiri-misaki (Cape Kawajiri), the present author has carried out a fairly continuous sampling of a number of test specimens from an area of one meter square of the outcrop belonging to entirely one rock block and has confirmed that the normal and the reverse natural remanent magnetism (N.R.M.) are found intermixed side by side in the very outcrop. On the other hand, the results of the thermo-magnetic analyses of the lava specimens suggest that the magnetic mineral responsible to the normal N.R.M. is predominantly a titanomagnetite of a phase having intermediate Curie point, whereas those to the reverse N.R.M. poly-phase having lower and higher Curie points than the intermediate. N. Kawai has recently proposed the idea that the self-reversal of remanent magnetism of rocks is possible to occur when the reverse magnetism of poly-phased titanomagnetites overcomes the rormal of the pre-existing, single-phased, parent one of which the exsolution has produced the poly-phased ones. Both the field evidence showing the positional close intermixing of the normal and the reverse magnetizations in the same lavas and the results of the author's laboratory experiments to prove the exsolution do not seem to favour the geomagnetic field reversal hypothesis.
\end{abstract}

\section{Introduction}

In the previous paper [1] were reported that the basalt lavas at Kawajirimisaki have in general reverse N.R.M., while in the belt B (Fig. 1) normal and reverse N.R.M. are found intermixed in positions, and also that for palaeomagnetic consideration a key may be afforded by a close field observation confirming whether the normally magnetized rocks are dykes penetrating the body of the reversely magnetized lavas or not, while on the other hand another interpretation seems to

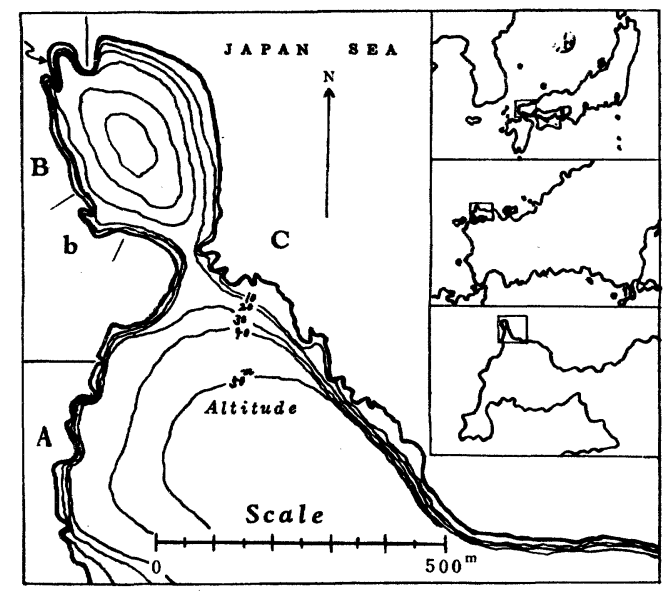

Fig. 1 A map of Kawajiri-misaki. be given by the self-reversal idea of remanent magnetism on the assumption that both 
the normally and the reversely magnetized rocks belong to the same lava block.

In this paper, it is reported that the present author has clarified by a close field observation that the normally magnetized rocks are not dykes and the fact of the positional intermixing of the normal and the reverse magnetizations in the same lava blocks can be explained by the self-reversal idea of remanent magnetism.

\section{Field observation}

Since the previous study, it has been a question whether the normal and the reverse magnetizations are intermixed in the really same rock block or not. Therefore, for the purpose of clarifying this, the author has intended to perform a close field observation and has carried out further close sampling of numerous specimens about 180 in number from an outcrop extending over a distance of about 50 meters in the

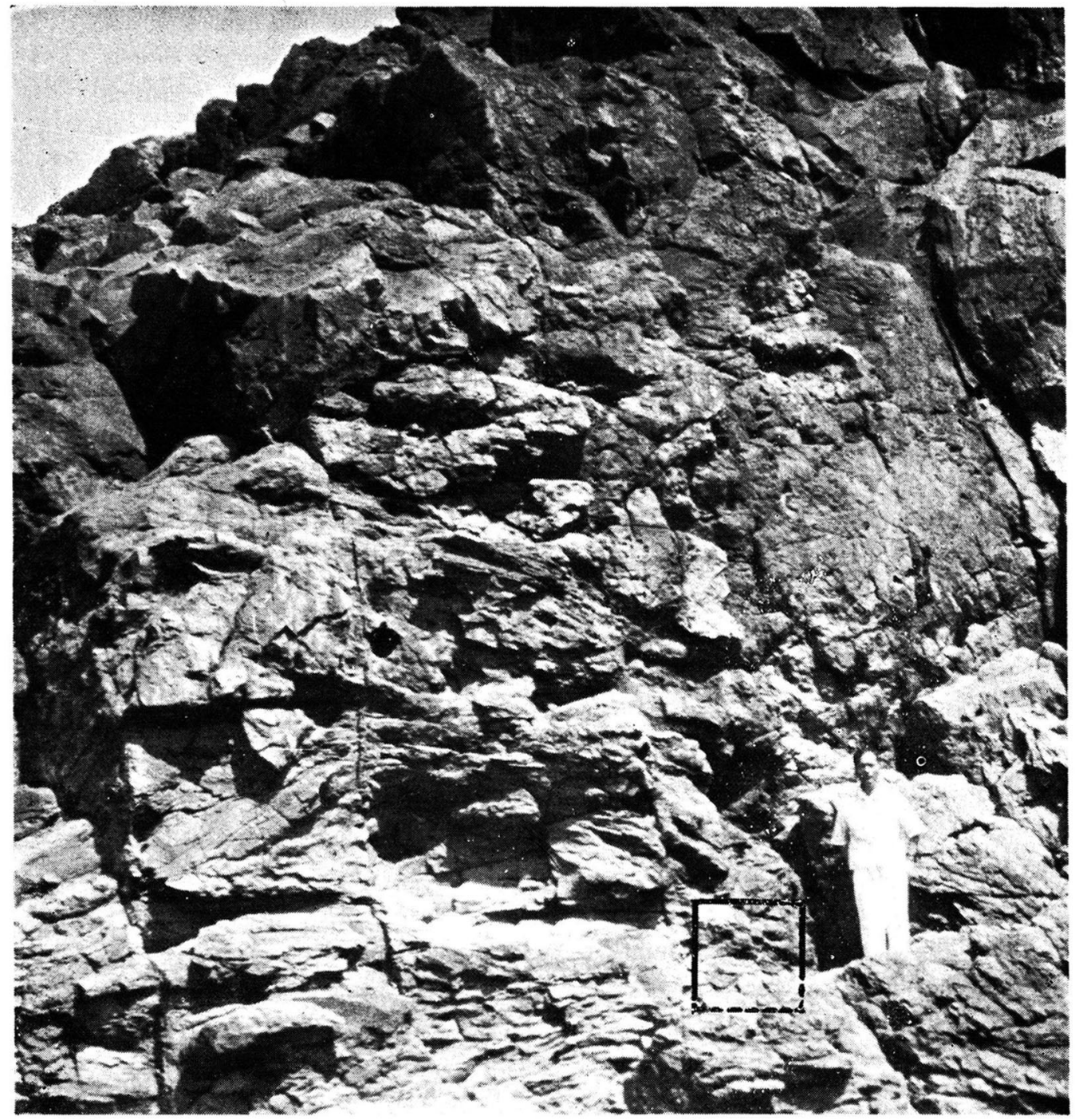

Fig. 2 A photcgraph of the sampling place i. Kawajiri-misaki lavas. 
northern part indicated by an arrow in Fig. 1 of the belt B. Finally, at a place of this outcrop he has succeeded in getting a fairly continuous sampling of a number of test specimens from an area of one meter square and has confirmed the fact that the normal and the reverse N.R.M. are found with their positions as intermixed side by side within such a small area.

Fig. 2 is a photograph of this sampling place. It is situated 7 meters high above the sea level in the middle of a rock-cliff of the Kawajiri-misaki lavas and sandwiched between two adjacent, vertical joints separated by a distance of 1.4 meter as can easily be seen in the photograph. This clearly indicates that the specimens from this place belong to the same and one rock block. The arrangement of the specimens in situ which he has sampled is represented in Fig. 3 which shows a side view of the fairly vertical surface of the area sampled. The directions and intensities of the N.R.N. of these specimens 26 in number have been measured by means of an astatic magnetometer. The results are shown in Fig. 4 and Table I. Fig. 4 is the Wulff's projections of the directions of the N.R.M. thus measured and in Table I are shown the intensities of the N.R.M.

As can be seen from Fig. 4, two specimens of No. 3 and No. 16 show normal magnetization, while the remaining 24 specimens are all

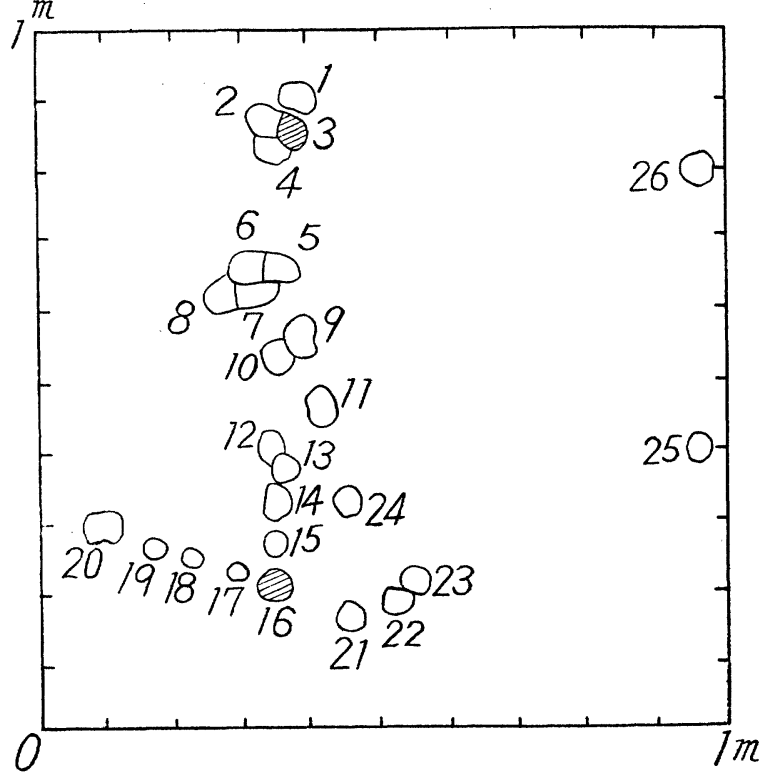

Fig. 3 The arrangement of 26 specimens sampled. Two specimens of No. 3 and No. 16 : normal magnetization

The remaining 24 specimens: reverse magnetization

Table I Intensities of the N.R.M. of 26 specimens in the unit of $10^{-4}$ c.g.s.e.m.u./g.

\begin{tabular}{|c|c|c|c|c|c|c|c|c|c|c|c|c|}
\hline $\begin{array}{c}\text { Speci- } \\
\text { men } \\
\text { No. }\end{array}$ & $\begin{array}{c}\text { Direc- } \\
\text { tion }\end{array}$ & $\begin{array}{c}\text { Inten- } \\
\text { sity }\end{array}$ & $\begin{array}{c}\text { Speci- } \\
\text { men } \\
\text { No. }\end{array}$ & $\begin{array}{c}\text { Direc- } \\
\text { tion }\end{array}$ & $\begin{array}{c}\text { Inten- } \\
\text { sity }\end{array}$ & $\begin{array}{c}\text { Speci- } \\
\text { men } \\
\text { No. }\end{array}$ & $\begin{array}{c}\text { Direc- } \\
\text { tion }\end{array}$ & $\begin{array}{c}\text { Inten- } \\
\text { sity }\end{array}$ & $\begin{array}{c}\text { Speci- } \\
\text { men } \\
\text { No. }\end{array}$ & $\begin{array}{c}\text { Direc- } \\
\text { tion }\end{array}$ & $\begin{array}{c}\text { Inten- } \\
\text { sity }\end{array}$ \\
\hline 1 & $\mathrm{R}$ & 5.2 & 8 & $\mathrm{R}$ & 4.0 & 15 & $\mathrm{R}$ & 6.7 & 22 & $\mathrm{R}$ & 9.3 \\
\hline 2 & $\mathrm{R}$ & 2.3 & 9 & $\mathrm{R}$ & 6.7 & 16 & $\mathrm{~N}$ & 4.0 & 23 & $\mathrm{R}$ & 9.0 \\
\hline 3 & $\mathrm{~N}$ & 1.2 & 10 & $\mathrm{R}$ & 5.7 & 17 & $\mathrm{R}$ & 7.8 & 24 & $\mathrm{R}$ & 8.1 \\
\hline 4 & $\mathrm{R}$ & 5.1 & 11 & $\mathrm{R}$ & 5.6 & 18 & $\mathrm{R}$ & 8.2 & 25 & $\mathrm{R}$ & 4.7 \\
\hline 5 & $\mathrm{R}$ & 4.2 & 12 & $\mathrm{R}$ & 6.1 & 19 & $\mathrm{R}$ & 9.5 & 26 & $\mathrm{R}$ & 4.0 \\
\hline 6 & $\mathrm{R}$ & 5.3 & 13 & $\mathrm{R}$ & 6.5 & 20 & $\mathrm{R}$ & 5.1 & & & \\
\hline 7 & $\mathrm{R}$ & 5.1 & 14 & $\mathrm{R}$ & 7.2 & 21 & $\mathrm{R}$ & 8.8 & & & \\
\hline
\end{tabular}




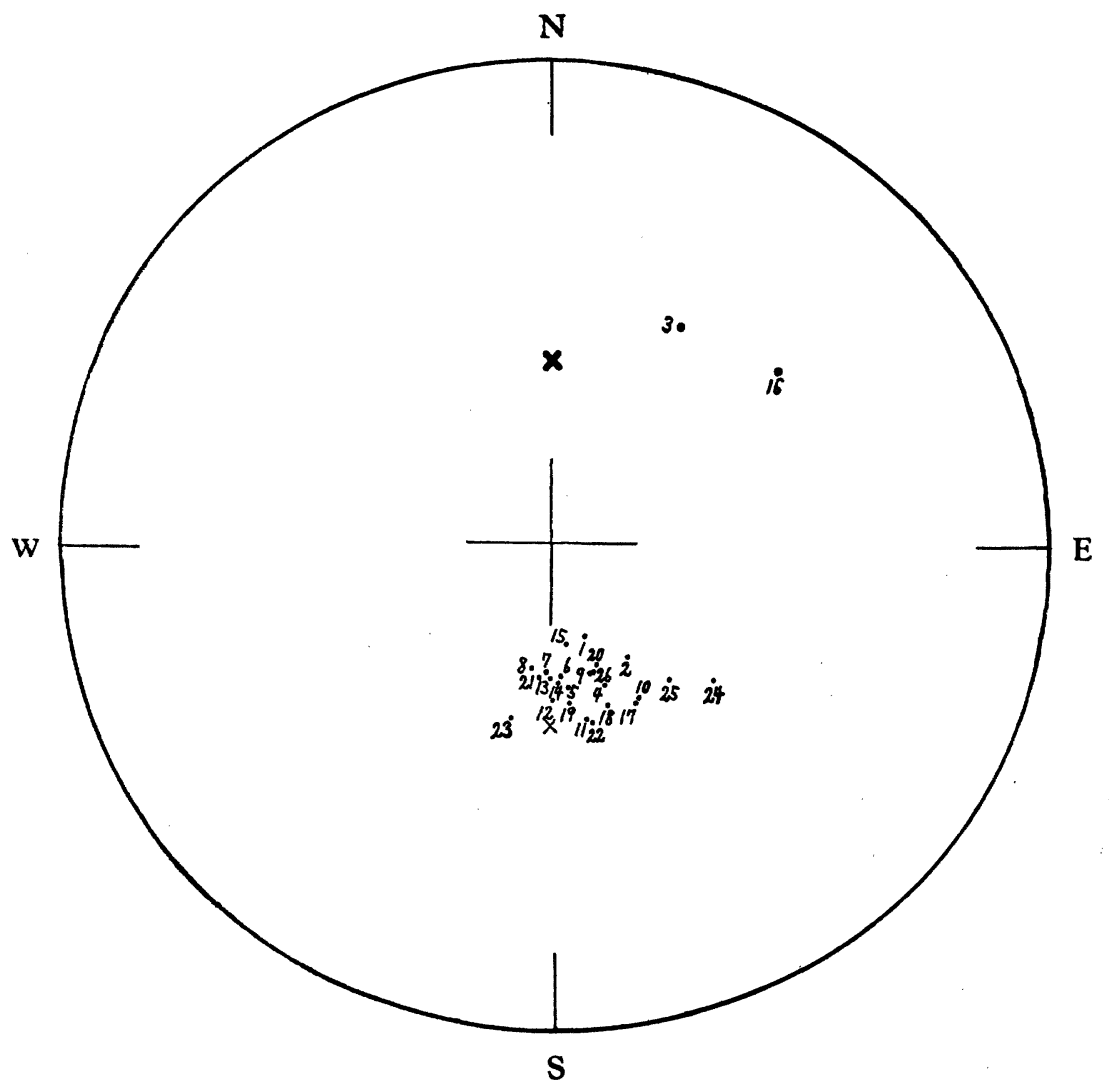

Fig. 4 Directions of the N.R.M. of 26 specimens.

Big plots represent the lower hemisphere and thin the upper. The thick cross $(x)$ indicates the direction of the present geomagnetic field at Kawajiri-misaki whose dip is $+49^{\circ}$ downward.

reverse and there is no magnetizations having intermediate directions. It is also worth noticing that the intensities of magnetization of these 26 specimens are in the order of magnitude of $10^{-4}$ c.g.s.e.m.u./g. being far less than $10^{-2}$ c.g.s.e.m.u./g. of the normally magnetized specimens in the partial belt b. [1]

Thus, as for the basalt lavas at Kawajiri-misaki it has been confirmed that the normal and the reverse magnetizations are intermixed in positions in entirely one rock block. Moreover, the author already reported [2] that microscopic observations can hardly recognize any petrological differences between the normal and the reverse specimens of the lavas.

From these facts, it may be naturally considered that the normally and the reversely magnetized rocks would have been formed in the really same lavas of simultaneous eruption. And it is quite unlikely that two lavas of different eruption times were extruded by being intermixed side by side with the structure of mosaic pattern in such a narrow space as the above field observation shows and that the directions of the geomagnetic field at the two different eruption times were opposite each other. 


\section{Thermo-magnetic analysis}

On 193 specimens [1] from the total region of Kawajiri-misaki, the present author has conducted some laboratory experiments. Carrying out thermo-magnetic analyses, he has obtained the temperature dependency of the intensity of saturation magnetization $\left(J_{s}-T\right.$ curve) for 36 specimens by random selection from among the above 193 specimens. The measurements have been done by the method of samplesealing. [3] Some typical examples of the $J_{s}-T$ curves are shown in Fig. 5.
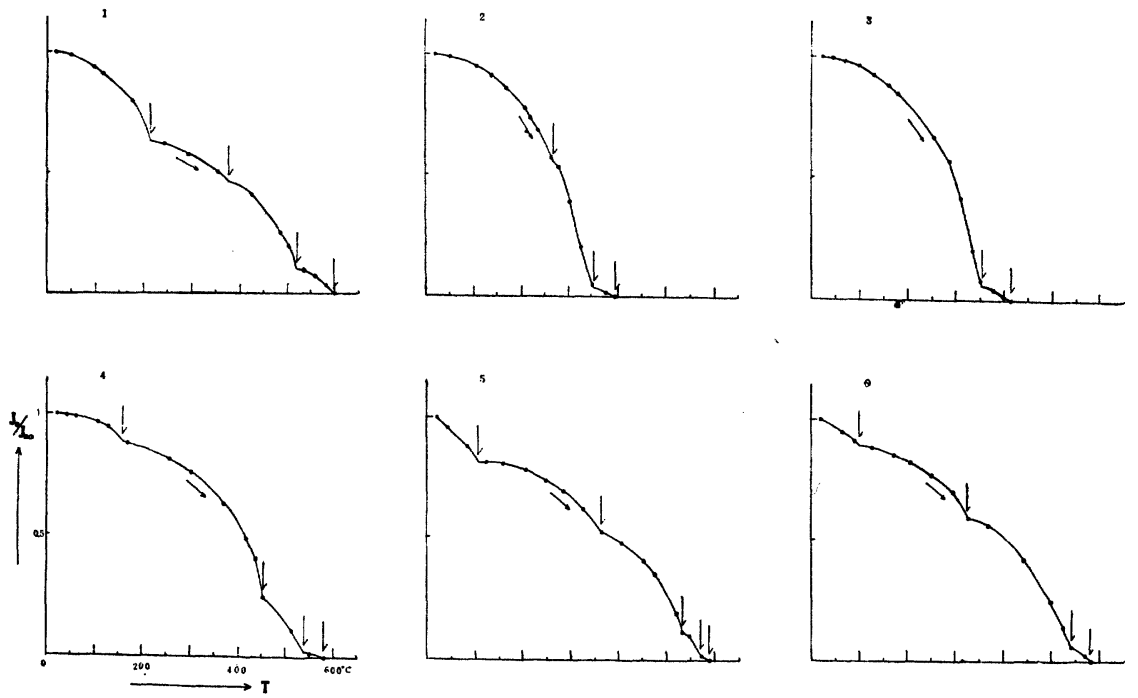

Fig. 5 Some examples of $\int_{s}-T$ curves.

$1,2,3$ : normal specimen

$4,5,6$ : reverse specimen

As will be seen from Fig. 5, there are several discontinuities of tangent of the curve; they suggest the Curie points of the different constituent phases of the ferromagnetic minerals in the specimen. In other words, it is noticed that the magnetic minerals of Kawajiri-misaki lavas are, generally speaking, not composed of a single phase but of several phases different in Curie points.

Observing various Curie points from each $J_{s}-T$ curve for these 36 specimens, H. Domen [4] has obtained the Curie point v.s. frequency relations for the normal and the reverse specimens. The result is illustrated in Fig. 6 in which he notices a definite difference between the normal and the reverse specimens.

Fig. 6 leads the present author to recognize that the frequency of Curie point for the normally magnetized specimens shows three peaks, of which the middle one occurring at the intermediate temperature about $370^{\circ} \mathrm{C}$ has a distinct maximum frequency and the remaining two peaks occurring at temperatures lower and higher than the intermediate are not sharp; and on the contrary the frequency for the reversely magnetized specimens shows two distinct peaks occurring at a low temperature about $120^{\circ} \mathrm{C}$ and a high one about $560^{\circ} \mathrm{C}$, which temperatures may be essentially identified with those of the above-mentioned, remaining, two peaks of the normal specimens, and 


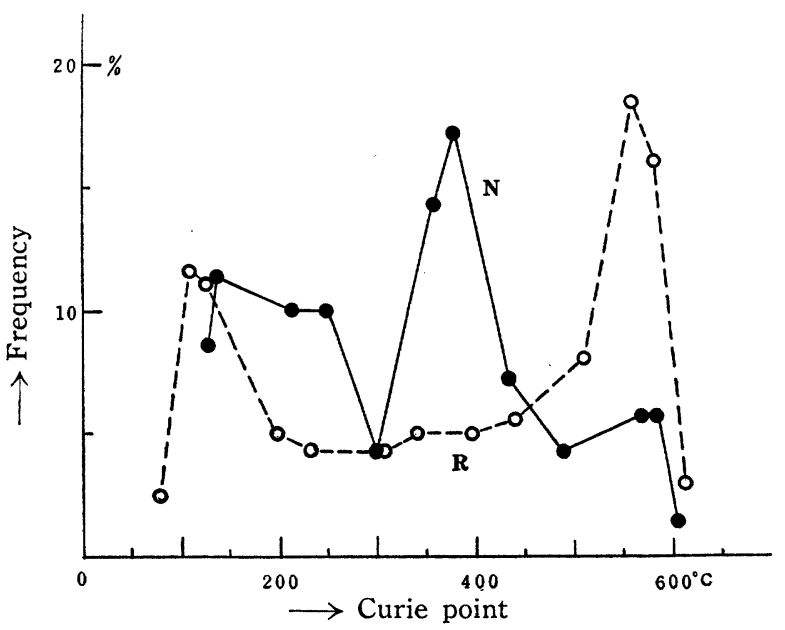

Fig. 6 Curie point v.s. frequency relation. $\mathrm{N}$ : normal specimen

$\mathrm{R}$ : reverse specimen (After H. Domen) it is worth noting that at the intermediate temperature, where does occur the maximum frequency of the normal specimens, a flat minimum frequency of the reverse specimens is found. Briefly speaking, the Curie points for the normal specimens are found predominantly at intermediate temperature, whereas those for the reverse are predominant both at lower and higher temperatures than the intermediate.

\section{Palaeomagnetic consideration}

Next, the present author would like to put a palaeomagnetic

consideration on the facts found at Kawajiri-misaki lavas.

Undoubtedly, the facts of the positional intermixing within a small area of the normal and the reverse magnetizations mentioned in section 2 do not seem to favour the geomagnetic field reversal hypothesis [5] postulated by T. Nagata and others with whom the present author joined that the reverse N.R.M. of the lavas would have been caused by a reverse geomagnetic field assumed to have occurred at the time of extrusion of the lavas. It is very likely that the positional intermixing of the normal and the reverse N.R.M. of the lavas would have been caused by the self-reversal mechanism of remanent magnetism, in other words, the whole basalt lavas at Kawajiri-misaki were extruded from the same origin and by the same eruption in the early Pleistocene age, by cooling they acquired originally a definite direction of magnetization which might be normal or reverse and the self-reversal of remanent magnetism would have afterwards occurred by a certain physical mechanism within the lavas to produce the positional intermixing of the normal and the reverse magnetizations.

The following three facts of the N.R.M. of 193 specimens already reported in the previous paper [1] seem to support the self-reversal idea of remanent magnetism. The first is the above-mentioned fact of the positional intermixing of the normal and the reverse magnetizations. The second is the fact that the intensities of magnetization are not uniform, ranging from $10^{-2}$ to $10^{-4}$ c.g.s.e.m.u./g. These can be easily explained as the results of magnetization corresponding to various stages of the selfreversal process up to the present time. The third is the fact that the directions of magnetization are not random but are, roughly speaking, either parallel or anti-parallel to the present geomagnetic field, with no intermediate directions. Moreover, both in the normal and the reverse specimens the directions of magnetization converge fairly well when their intensities of magnetization are very great being in the order of magnitude of $10^{-2}$ e.g.s.e.m.u./g., while they diverge far wider when very low being 
$10^{-4}$ c.g.s.e.m.u./g. Of 5 normal specimens belonging to the converging group, the standard deviations of the directions from their average value are $8.2^{\circ}$ in declination and $3.3^{\circ}$ in dip. Of 10 normal specimens belonging to the diverging group, the standard deviations are $17.6^{\circ}$ in declination and $19.9^{\circ}$ in dip. Besides, in addition to the above 193 specimens there are found more than 10 specimens having very weak magnetizations less than $10^{-4}$ c.g.s.e.m.u./g. and in their directions intermediate ones are found besides the normal and the reverse. This fact may suggest that at certain points of the lavas the intensity of magnetization might have turned into nearly zero as a result of self-reversal. The divergence in the directions of the N.R.M. whose intensities are in the order of magnitude of $10^{-4}$ c.g.s.e.m.u./g. and the existence of the intermediate directions occurring to the N.R.M. less than $10^{-4}$ c.g.s.e.m.u./g. are the natural consequence of the self-reversal phenomenon, as the direction of the field the parent ferromagnetic particle is producing is not always exactly anti-parallel to the direction of magnetization of the parent.

However, it is yet difficult to conclude from these field evidences whether the original magnetization of the lavas was normal or reverse. But, from the results of the thermo-magnetic experiments stated in section 3, a key of the solution can be given as shown below.

It was already reported [5] that the main ferromagnetic mineral in all the Kawajiri-misaki rocks is titanomagnetite and of both the normal and the reverse specimens the N.R.M. is mainly due to the thermo-remanent magnetism (T.R.M.). N. Kawai and others [6] have recently proposed the idea that the self-reversal of remanent magnetism of rocks is possible to occur by means of exsolution in ferromagnetic minerals of titanomagnetite series which has occurred after the original acquisition of T.R.M. took place. From the results of their experimental research on some eruptive rocks (other than the Kawajiri-misaki basalt) which possess reverse N.R.M. and whose ferromagnetic minerals are composed mainly of the solid solution between $\mathrm{Fe}_{3} \mathrm{O}_{4}$ and $\mathrm{TiO}_{2} \mathrm{Fe}_{2} \mathrm{O}_{2}$, they explain the process of self-reversal. The essential part of their explanation needed to the present author is as follows: At the time of formation of the rocks, the direction of magnetization was coincident with that of the geomagnetic field at this time and the magnetic mineral responsible to the magnetization was a homogeneous titanomagnetite with a certain Curie point. Then through a long period in geological time scale since the formation of the rocks, a fractional part of the parent titanomagnetite (single phase) broke up successively into two phases, one having higher Curie point and the other lower than that of the parent single-phase, and at least more than two kinds of precipitates produced by the exsolution were magnetized in the direction of the field produced by the pre-existing, parent titanomagnetite; and this direction may be assumed to be generally opposite to the direction of magnetization of the parent. Consequently, the remanent magnetism of the rocks we recognize at present is regarded as the resultant of the original magnetization of the remaining, parent phase and the opposite one of the precipitates. Hence, when the magnetization of the parent overcomes that of the precipitates, the direction of the 
N.R.M. coincides with that of the geomagnetic field at the time of formation of the rocks. However, when the magnetization of the precipitates overcomes that of the parent, the direction of the N.R.M. is to be found opposite to that of the geomagnetic field at the time of formation of the rocks.

The results of the thermo-magnetic analyses of Kawajiri-misaki lava specimens seem to be consistent with this self-reversal idea of remanent magnetism. Besides, it has also been ascertained that the Kawajiri-misaki lava specimens indicate the same characteristics as demonstrated by N. Kawai's experiments [6] that the sudden inversions of the direction of magnetization of the specimen take place when it is continuously heated. The results mentioned in section 3 suggest that the magnetic mineral responsible to the normal N.R.M. of the Kawajiri-misaki lavas is predominantly a titanomagnetite of a phase having intermediate Curie point, whereas those to the reverse N.R.M. poly-phase having lower and higher Curie points than the intermediate. Thus, from the author's results of these thermo-magnetic experiments and N. Kawai's idea of self-reversal phenomenon due to exsolution, the following interpretation is possible for the observed facts of the N.R.M. of the Kawajiri-misaki lavas.

In the early Pleistocene age, about a million years ago, when the Kawajirimisaki lava was extruded, the geomagnetic field was normal. In the course of cooling of the lava, the single-phased titanomagnetite acquired T.R.M. after it had cooled below its Curie point about $370^{\circ} \mathrm{C}$ in the direction of this geomagnetic field. This is the original magnetization of the lava and the direction of magnetization is normal. Since this magnetization, the single-phased titanomagnetite underwent exsolution giving rise to children of different titanomagnetites having Curie points lower and higher than that of the parent. By the field of the parent titanomagnetite, magnetization would have occurred on some children titanomagnetites having the lower Curie points, provided that they are lower than the temperature to which these children titanomagnetites were exposed when magnetized; and the direction of magnetization of these children was generally opposite to the direction of magnetization of the parent. Until the present time, new children titanomagnetites came into existence one after another and similar opposite magnetization occurred, resulting in increasing the total intensity of the opposite magnetization and at the same time in decreasing that of the original magnetization within a small volume of the lava. As mineralogical composition of the lava at the time of its solidification would have been different from point to point, the relative magnitudes of the present opposite magnetization and original one should be different from point to point of the outcrop of the Kawajiri-misaki lava. Consequently, the N.R.M. of a volume of hand specimen size in which the present total intensity of the original magnetization overcomes that of the opposite one is to be found normal, while that in which the present total intensity of the opposite magnetization overcomes that of the original is to be found reverse. The fact of the positional close intermixing of the normal and the reverse N.R.M. whose intensities are as weak as $10^{-4}$ c.g.s. e. m. u./g. in order of magnitude within entirely one rock block shown in section 2 can be reasonably explained as the results of magnetization corres- 
ponding to the condition that at any points in the rock block two intensities of the present original magnetization and opposite one amount to fairly comparable magnitudes and one slightly overcomes the other according to the sampling position.

If we assume that the direction of the geomagnetic field at Kawajiri-misaki in the early Pleistocene age was opposite to that of the present geomagnetic field, the maximum frequency of the intermediate Curie point (the parent titanomagnetite) should be found not for the normal specimens but for the reverse. But our observed fact of the Curie point v.s. frequency relation is reverse to this, suggesting that the reverse N.R.M. of the Kawajiri-misaki lavas hardly favour the geomagnetic field reversal hypothesis.

\section{Acknowledgements}

The author's hearty acknowledgements are first due to Emeritus Prof. M. Matuyama and Prof. M. Hasegawa, under whose directions his study has been carried out. The author also wishes to express his deep gratitudes to Prof. N. Kumagai for important suggestions and discussions extended throughout this work and also to Lecturer N. Kawai for helpful supports and discussions. He is also grateful to Prof. T. Nagata, Prof. Y. Kato and Mr. S. Akimoto for valuable criticisms. The author's sincere thanks are also due to Prof. P.M.S. Blackett for his cordial attention to this study. He is also indebted to Messrs. H. Domen, T. Yoshidomi and T. Sakata of Yamaguchi University for assistances in this work.

\section{References}

[1] E. Asami, Journ. Geomag. Geoele., 6, 145 (1954).

[2] E. Asami and H. Domen, Journ. Yamaguchi Univ., 6, 70 (1955) (in Japanese).

[3] N. Kumagai, N. Kawai and S. Kume, Memo. Coll. Sci. Univ. Kyoto, 21, 287 (1954).

[4] H. Domen, Kagaku (Science), 26, 145 (1956) (in Japanese).

[5] T. Nagata, S. Akimoto, S. Uyeda, K. Momose and E. Asami, Tech. Comm. Palaeomag., Xth Assembly, ATME, IUGG, Rome, 29 (1954); Journ. Geomag. Geoele. 6, 182 (1954).

[6] N. Kawai, S. Kume and S. Sasajima, Proc. Jap. Acad., 30, 588, 864 (1954), 31, 346 (1955). 